\title{
VIABILIDADE ECONÔMICA DA IMPLANTAÇÃO DE UM SISTEMA DE EQUIPAMENTOS ECONOMIZADORES DE ÁGUA E DE CAPTAÇÃO DE ÁGUA PLUVIAL PARA RESIDÊNCIA UNIFAMILIAR
}

\author{
Taís Bertolini $^{*}$, Adalberto Pandolfo ${ }^{1}$, Ritielli Berticelli ${ }^{1}$, Eduardo Madeira Brum $^{1}$ e \\ Pâmela Bia Pasquali ${ }^{1}$
}

\section{RESUMO}

BERTOLINI, T.; PANDOLFO, A.; BERTICELLI, R.; BRUM, E. M.; PASQUALI, P. B. Viabilidade econômica da implantação de um sistema de equipamentos economizadores de água e captação de água pluvial para residência unifamiliar. Perspectivas Online: Exatas \& Engenharias,

A água é um recurso imprescindível e extremamente importante para a sobrevivência humana, porém sua disponibilidade está se tornando cada vez mais escassa com o passar dos anos. Este trabalho visa um estudo da viabilidade econômica da implantação de um sistema com a utilização de equipamentos economizadores de água com tecnologia para a redução de vazão, de um sistema de captação de água pluvial para uso geral e de ambos utilizados simultaneamente, que além de serem alternativas simples, adequadas e de alcance social, fazem uma grande diferença reduzindo o desperdício e o consumo. Após estudo e levantamento preliminar a respeito das características locais e dos materiais necessários, foi realizada uma listagem dos gastos desses sistemas e da porcentagem de redução das taxas de consumo diário comparado com um sistema convencional de abastecimento em uma edificação residencial unifamiliar. Com isso foi criado um fluxo de caixa com o investimento inicial e a economia anual de cada um, sendo verificado que o sistema que prevalece com a maior economia, levando em consideração uma taxa mínima de atratividade de $8 \%$, foi o de equipamentos economizadores de água com um período de retorno de 10 meses após iniciada a utilização, sendo viável economicamente.

Palavras-chave: Avaliação Econômica de Projetos; Redução no consumo de água; Sistemas de economia. 


\begin{abstract}
Water is an indispensable and extremely important resource for human survival, but its availability is becoming increasingly scarce over the years. This work aims at a study of the economic feasibility of the implantation of a system with a use of water saving equipment with technology for a reduction of flow, a rainwater capture system for general use and both uses simultaneously, which besides being simple, adequate alternatives and of social reach, make a great difference reduced or waste and consumption. After a preliminary study and survey of the

local characteristics and necessary materials, a list was made of the system costs and the percentage reduction of the rates of daily consumption compared to a conventional system of supply in a single-family residential building. With this, a cash flow was created with the initial investment and annual savings of each one, and it was verified that the system that prevails with a bigger economy, taking in a rate of minimum attraction rate of $8 \%$, was the drinking water equipment with a return period of 10 months after starting the utilization, being economically viable.
\end{abstract}

Keywords: Economic Evaluation of Projects; Reduction in water consumption; Economics systems.

\footnotetext{
${ }^{1}$ Universidade de Passo Fundo - UPF - Laboratório de Engenharia - BR 285, São José, Passo Fundo, RS, CEP: 99052-900, Brasil.

(*) e-mail: ritiberticelli@hotmail.com

Data de recebimento: 07/04/18. Aceito para publicação: 18/11/18.
}

Persp. Online: exatas \& eng., Campos dos Goytacazes, 23 (08) 01-17 - 2018

seer.perspectivasonline.com.br 


\section{INTRODUÇÃO}

De acordo com a Organização das Nações Unidas (ONU, 2015), estima-se que a partir de 2030 o planeta enfrentará um déficit de $40 \%$ de água caso não sejam tomadas medidas que proporcionem uma melhoria na gestão desse recurso.

Propostas para que se possam realizar economias através de sistemas de captação de água pluvial com utilização destinada para fins não potáveis e também a implantação de equipamentos economizadores de água para redução de vazão, além de atender estes aspectos ambientais, proporcionam benefícios econômicos, sendo simples, acessíveis e de fácil instalação.

As tendências atuais de consumo revelam que não haverá água suficiente, e de qualidade para atender às crescentes necessidades mundiais, sem que se altere radicalmente a forma como esses recursos são utilizados. $\mathrm{O}$ autor afirma que este é o momento para se traçar um novo rumo, alterando as práticas e ações que favoreçam o desenvolvimento a um significativo custo ambiental e social (BOKOVA, 2015).

Segundo Sistema Nacional de Informações sobre Saneamento (SNIS, 2016), o consumo médio de água per capita no Brasil foi de 160 litros por dia para o ano de 2014, porém estados, como o Rio de Janeiro, por exemplo, chegam a consumir 250,8 litros por dia. O Rio Grande do Sul consome em média 162,9 litros por dia. O recomendado é que cada pessoa utilize cerca de 110 litros por dia, volume este considerado suficiente para que se possa atender as necessidades de consumo e de higiene.

Com os equipamentos economizadores de água é possível evitar o desperdício, pois o uso torna-se cauteloso em virtude de que o sistema não permite a vazão excessiva, o mau fechamento e a utilização por tempo prolongado além do necessário. Diminuindo o consumo de água, consequentemente haverá menos geração de esgoto.

Conforme May (2004), o aproveitamento da água pluvial para fins domésticos, agrícolas e industriais está ganhando ênfase por ser considerado um meio simples e eficaz para atenuar o problema da escassez de água para consumo.

De acordo com O2 Engenharia (2008), o aproveitamento de água pluvial surge como medida para tentar resolver dois graves problemas. A drenagem urbana e a escassez da água. A drenagem urbana contribui para a redução das enchentes, retirando do sistema de drenagem um grande volume de água, já que grande parcela está sendo captada e reservada. Além disso, com a utilização da água pluvial haverá diminuição no consumo de água potável, proporcionando redução na conta de água.

À frente deste assunto, o objetivo desta pesquisa é verificar a viabilidade econômica da implantação de um sistema de equipamentos economizadores de água e de captação de água pluvial, visando uso consciente e racional da água, buscando economia, diminuindo o desperdício e proporcionando conservação de recursos e premissas sustentáveis. 


\section{METODOLOGIA}

\subsection{Descrição do objeto de estudo}

O estudo refere-se a avaliação econômica de um sistema para economia de água potável em uma residência unifamiliar, com dois pavimentos e área de $130,80 \mathrm{~m}^{2}$ em cada pavimento. $\mathrm{O}$ terreno possui suas dimensões de $12 \mathrm{~m}$ x $27 \mathrm{~m}$, com uma área de $324 \mathrm{~m}^{2}$.

A residência possui estrutura de concreto armado, com fechamento em alvenaria e cobertura de telhas cerâmicas, tendo como complemento os condutores horizontais, as calhas e os condutores verticais, que transportam a água para descarte. Estes componentes também são utilizados para o sistema de captação pluvial, mas como já estão inclusos na estrutura, não contabilizou no comparativo da viabilidade econômica.

\subsection{Procedimento Metodológico}

Este trabalho foi dividido em três etapas, sendo realizado conforme o fluxograma da Figura 1.

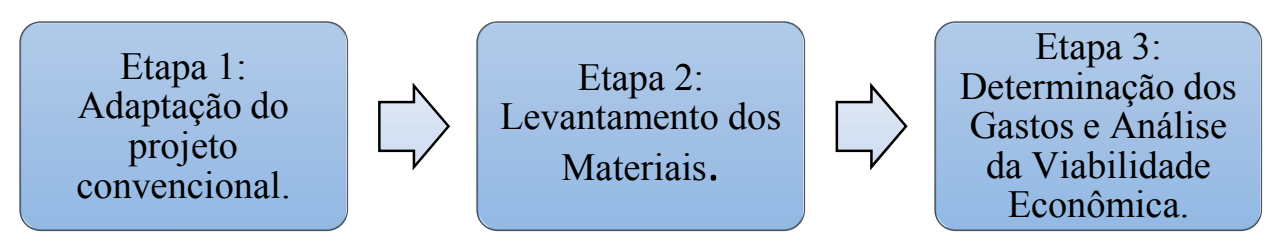

Figura 1: Fluxograma de atividades.

\section{Etapa 1 - Adaptação do projeto convencional}

A adaptação do projeto convencional será feita a fim de incluir o sistema de equipamentos economizadores de água e de captação de água pluvial. Para complementar o sistema convencional, a residência contará com o acréscimo de dois reservatórios, sendo um inferior e outro superior. O reservatório inferior acondicionará a água recebida pelos condutores verticais, que antes passará por um filtro para recolhimento dos materiais grosseiros. Depois de armazenada a água, passará novamente por um processo de filtragem e será bombeada para o reservatório superior, sendo que este fará a distribuição para fins não potáveis, com a utilização em bacias sanitárias, para a lavagem de roupas, de calçadas, de automóveis e também para jardins. A residência contará com equipamentos economizadores de água para a diminuição de vazão.

A água proveniente da chuva que extravasar o volume do reservatório irá para a drenagem, e caso ocorra o contrário, na hipótese de que haja falta de água pluvial, com a utilização de um realimentador, a água potável será utilizada para o suprimento, onde a mesma está em um reservatório separado com uma tubulação independente, na qual não há a mistura entre os dois tipos de água. 
Foi realizado um levantamento da quantidade de água captada, de acordo com a precipitação mensal, da área de captação, do coeficiente de escoamento superficial da cobertura e da eficiência do sistema de captação.

Os dados de precipitação pluviométrica foram obtidos conforme o banco de dados disponibilizado pela Embrapa Trigo de Passo Fundo - RS (EMBRAPA TRIGO, 2016).

A área de captação foi considerada de acordo com a área de cobertura do projeto.

A determinação da previsão do consumo mensal de água varia de acordo com a quantidade de moradores e com porcentagem de utilização de cada equipamento. Foi considerada quantidade de água gasta em cada tipo de utilização segundo Oliveira, conforme citado por Scortegagna, Da Silva \& Fernandes (2005).

\section{Etapa 2 - Levantamento dos materiais necessários}

A escolha dos equipamentos necessários para o sistema de captação de água pluvial e dos equipamentos economizadores de água foi definida de acordo com uma comparação realizada pela Fecomercio (2010) entre os equipamentos convencionais e os economizadores com a sua diferença de consumo. A escolha dos equipamentos foi realizada de acordo com a porcentagem de redução e a quantidade de bacias sanitárias, de duchas e de torneiras que serão utilizadas, conforme consta no projeto e no memorial descritivo.

Com a determinação da precipitação e da demanda realizou-se a escolha do tamanho do reservatório através de catálogos de fornecedores. Foi necessário obter primeiro estes parâmetros para que o mesmo não seja superdimensionado e também porque o volume aproveitado de água não é o mesmo que o volume precipitado. O diâmetro das tubulações e os filtros foram escolhidos conforme necessidade do sistema. A bomba pressurizadora foi definida de acordo com a potência para o transporte de água até o reservatório superior.

O levantamento foi através de tabelas para melhor organização e posterior pesquisa de valores, com o detalhamento e as características de cada material.

\section{Etapa 3 - Determinação dos gastos e realização da análise da avaliação econômica}

Com todos os parâmetros definidos a respeito dos materiais utilizados e com as suas quantidades, realizou-se a orçamentação estimada através de um levantamento dos custos nas lojas da região e da mão-de-obra para sua instalação, visando a escolha daquele que determinar um produto de boa qualidade, com preços acessíveis e objetivando um melhor custo-benefício.

Definida a demanda mensal necessária para a residência em relação ao consumo de água, foi realizada uma verificação de quantos $\mathrm{m}^{3}$ seria economizado através do sistema de captação e também da economia referente aos equipamentos redutores de vazão.

A economia financeira levou em conta as tarifas estabelecidas pela concessionária, no caso a Companhia Riograndense de Saneamento (Corsan), de acordo com a categoria da edificação.

Persp. Online: exatas \& eng., Campos dos Goytacazes, 23 (08) 01-17 - 2018

seer.perspectivasonline.com.br 
Foi realizada uma comparação da conta mensal com utilização da água toda da concessionária, sem a utilização do sistema, com a conta do valor mensal com os sistemas de economia de água.

Após a determinação do investimento necessário para a implantação verificou-se a viabilidade econômica. Os métodos utilizados foram o Valor Presente Líquido (VPL), a Taxa Interna de Retorno (TIR) e análise de retorno de investimento (PAYBACK), considerando um horizonte de investimento de 15 anos.

\section{FASE DE ADAPTAÇÃO E LEVANTAMENTO DE MATERIAIS}

\subsection{Determinação da água pluvial aproveitável}

A quantidade de água captada que pode ser aproveitável depende de diversos fatores que podem influenciar na determinação deste volume. Sendo eles a precipitação, área de captação, coeficiente de escoamento da cobertura e a eficiência do sistema de captação.

\subsubsection{Precipitação}

Dados de precipitação que estão apresentados na Tabela 1 foram levantados no período de maio de 2015 até abril de 2016.

Tabela 1: Precipitação pluvial recente para a cidade de Passo Fundo.

\begin{tabular}{cc}
\hline Mês & Precipitação pluvial (mm) \\
\hline Maio/15 & 166,3 \\
Junho/15 & 172,8 \\
Julho/15 & 322,5 \\
Agosto/15 & 55,0 \\
Setembro/15 & 200,4 \\
Outubro/15 & 264,0 \\
Novembro/15 & 208,7 \\
Dezembro/15 & 347,0 \\
Janeiro/16 & 190,3 \\
Fevereiro/16 & 225,7 \\
Março/16 & 205,0 \\
Abril/16 & 188,5 \\
\hline
\end{tabular}

\subsection{2 Área de captação}

A área de captação será de acordo com a área de cobertura do projeto, sendo esta de 134,05 metros quadrados. 


\subsubsection{Coeficiente de escoamento superficial da cobertura}

O Coeficiente de Escoamento Superficial utilizado será de 0,85, conforme Método Racional, sendo este o coeficiente médio para telhas cerâmicas, já que para essas telhas o fator pode variar entre 0,8 a 0,9 de acordo com Tomaz (2009).

\subsubsection{Eficiência do sistema de captação}

O fator de eficiência utilizado foi de 0,8 , de acordo com Pereira \& Santos (2013) que aponta que quando não há dados específicos a respeito dos filtros e telas, um valor prático a ser adotado é de 0,8 .

\subsubsection{Cálculo do volume de água aproveitável}

Na Tabela 2 são representados os parâmetros utilizados para o cálculo que não irão variar, sendo o único que pode alterar é a precipitação. O volume de água da chuva que pode ser aproveitável referente a cada mês do ano está apresentado na Tabela 3.

Tabela 2: Resumo dos Parâmetros Utilizados.

\begin{tabular}{lcc}
\hline \multicolumn{2}{c}{ Parâmetros } & \\
\hline Área de Captação $\left(\mathrm{m}^{2}\right)$ & 05 & 134, \\
Coeficiente de Escoamento Superficial & & 0,85 \\
Eficiência do Telhado & 0,8 \\
\hline
\end{tabular}

Tabela 3: Volume de água aproveitável.

\begin{tabular}{cccc}
\hline Mês & $\begin{array}{c}\text { Precipitação } \\
\text { pluvial }(\mathbf{m m})\end{array}$ & $\begin{array}{c}\text { Volume Captação pela } \\
\text { cobertura }\left(\mathbf{m}^{\mathbf{3}}\right)\end{array}$ & $\begin{array}{c}\text { Volume } \\
\text { aproveitável }\left(\mathbf{m}^{\mathbf{3}}\right)\end{array}$ \\
\hline Janeiro & 149,7 & 20,07 & 13,65 \\
Fevereiro & 165,8 & 22,23 & 15,11 \\
Março & 134,9 & 18,08 & 12,30 \\
Abril & 99,7 & 13,36 & 9,90 \\
Maio & 114,3 & 15,32 & 10,42 \\
Junho & 133,6 & 17,91 & 12,18 \\
Julho & 161,8 & 21,69 & 14,75 \\
Agosto & 187,8 & 25,17 & 17,12 \\
Setembro & 197,7 & 26,50 & 18,02 \\
Outubro & 152,9 & 20,50 & 13,94 \\
Novembro & 131,7 & 17,65 & 12,00 \\
Dezembro & 173,2 & 23,22 & 15,79 \\
\hline
\end{tabular}




\subsection{Consumo de água}

\subsubsection{Sistema convencional}

O consumo diário de água utilizado na presente pesquisa foi de 178,7 litros diários. Este valor está próximo do consumo médio atual do estado do Rio Grande do Sul, que é de 162,9 litros diários por habitante, conforme dados de 2014 fornecido por SNIS (2016). Nas Tabelas 4 e 5 são apresentados os consumos mensal de utilização em comum e diário individual para cada habitante, respectivamente.

Tabela 4: Consumo de utilização em comum.

\begin{tabular}{cc}
\hline Utilização em comum & $\begin{array}{c}\text { Consumo mensal } \\
\text { (litros) }\end{array}$ \\
\hline Lavar automóvel & 560 \\
Lavar Calçadas com mangueira & 1000 \\
Regar Jardim com mangueira & 1000 \\
\hline TOTAL & $\mathbf{2 5 6 0}$ \\
\hline
\end{tabular}

Tabela 5: Consumo individual para cada habitante.

\begin{tabular}{cc}
\hline Utilização & Consumo diário (litros) \\
\hline Descarga Bacia Sanitária & 30 \\
Chuveiro & 62 \\
Torneiras em geral & 3,6 \\
Cozinha & 50,8 \\
Lavar roupas & 11 \\
Utilização em comum por habitante & 21,3 \\
\hline TOTAL & $\mathbf{1 7 8 , 7 0}$
\end{tabular}

A estimativa do consumo doméstico de água foi em relação às 4 pessoas, no qual um dos moradores trabalha o dia todo, permanecendo em casa apenas na parte da noite, um segundo morador permanece praticamente todos os dias em casa, e os outros dois moradores permanecem em casa na parte da manhã e da noite durante os dias úteis, enquanto nos finais de semana, todos permanecem em casa na maior parte do tempo.

Dos 178,7 litros de água por pessoa que seriam consumidos diariamente, foi estimado um valor de 2,5\% deste volume a ser descontado de 4,48 litros de água por habitante, levando em consideração o consumo realizado fora do local de estudo pelos três moradores que possuem atividades fora da residência, volume este descontado da utilização da bacia sanitária e da cozinha. O consumo individual diário para a residência está representado na Tabela 6. 
Tabela 6: Consumo individual diário para a residência.

\begin{tabular}{cc}
\hline Utilização & $\begin{array}{c}\text { Consumo diário } \\
\text { (litros) }\end{array}$ \\
\hline Descarga Bacia Sanitária & 28 \\
Chuveiro & 62 \\
Torneiras em geral & 3,6 \\
Cozinha & 48,32 \\
Lavar roupas & 11 \\
Utilização em comum por & \\
habitante & 21,3 \\
\hline TOTAL & 174,22 \\
\hline
\end{tabular}

\subsubsection{Sistema de equipamentos economizadores de água}

A escolha dos equipamentos economizadores de água foi realizada de acordo com a porcentagem de redução de cada equipamento relacionado com o equipamento convencional. A Tabela 7 mostra os equipamentos utilizados de acordo com o tipo de uso, juntamente com a diferença de consumo antes e depois da instalação dos equipamentos e a quantidade de água economizada, o qual com a utilização dos equipamentos economizadores a economia diária será de 76,96 litros por habitante.

Tabela 7: Redução de consumo diário com a utilização de equipamentos economizadores de água.

\begin{tabular}{|c|c|c|c|c|c|c|}
\hline Uso & $\begin{array}{l}\text { Equipamento } \\
\text { Convencional }\end{array}$ & $\begin{array}{l}\text { Equipamento } \\
\text { Economizador }\end{array}$ & Redução & $\begin{array}{c}\text { Antes } \\
\text { (1/hab.dia) }\end{array}$ & $\begin{array}{c}\text { Depois } \\
\text { (l/hab.dia) }\end{array}$ & $\begin{array}{l}\text { Economia } \\
\text { (l/hab.dia) }\end{array}$ \\
\hline $\begin{array}{c}\text { Bacia } \\
\text { Sanitária }\end{array}$ & $\begin{array}{c}\text { Bacia } \\
\text { Sanitária } \\
\text { Caixa } \\
\text { Acoplada } 6 \\
\text { litros }\end{array}$ & $\begin{array}{l}\text { Bacia VDR } \\
\text { com } \\
\text { acionamento } \\
\text { seletivo }\end{array}$ & $40 \%$ & 28,00 & 16,80 & 11,20 \\
\hline Chuveiro & Ducha & $\begin{array}{l}\text { Restritor de } \\
\text { Vazão }\end{array}$ & $32 \%$ & 62,00 & 42,16 & 19,84 \\
\hline Torneiras & $\begin{array}{l}\text { Torneira de } \\
\text { Uso geral }\end{array}$ & $\begin{array}{l}\text { Arejador } \\
\text { Vazão }\end{array}$ & $62 \%$ & 3,60 & 1,37 & 2,23 \\
\hline Cozinha & $\begin{array}{c}\text { Torneira de } \\
\text { Pia }\end{array}$ & $\begin{array}{c}\text { Arejador } \\
\text { Vazão }\end{array}$ & $57 \%$ & 48,32 & 20,78 & 27,54 \\
\hline $\begin{array}{l}\text { Lavar } \\
\text { roupas }\end{array}$ & $\begin{array}{l}\text { Torneira de } \\
\text { Uso geral }\end{array}$ & $\begin{array}{l}\text { Regulador de } \\
\text { Vazão }\end{array}$ & $50 \%$ & 11,00 & 5,50 & 5,50 \\
\hline $\begin{array}{l}\text { Utilização } \\
\text { em } \\
\text { comum }\end{array}$ & $\begin{array}{c}\text { Torneira de } \\
\text { Uso geral }\end{array}$ & $\begin{array}{l}\text { Regulador de } \\
\text { Vazão }\end{array}$ & $50 \%$ & 21,30 & 10,65 & 10,65 \\
\hline \multicolumn{6}{|c|}{ ECONOMIA DIÁRIA (l/hab) } & 76,96 \\
\hline \multicolumn{6}{|c|}{ ECONOMIA MENSAL (l/hab) } & 2308,93 \\
\hline
\end{tabular}




\subsubsection{Sistema de captação de água pluvial}

O volume de água para fins não potáveis será considerado como sendo o volume utilizado em bacias sanitárias, na lavagem de roupas e para outras utilizações em comum. Na tabela 8 está representado o consumo antes e depois da implantação e também a economia de água potável. Com a utilização do sistema de captação de água pluvial por si só a economia diária será de 60,30 litros por habitante.

Tabela 8: Redução de consumo diário com a utilização do sistema de captação de água pluvial.

\begin{tabular}{|c|c|c|c|c|}
\hline Uso & $\begin{array}{l}\text { Equipamento } \\
\text { Convencional }\end{array}$ & $\begin{array}{c}\text { Antes } \\
\text { (l/hab.dia) }\end{array}$ & $\begin{array}{c}\text { Depois } \\
\text { (1/hab.dia) }\end{array}$ & $\begin{array}{r}\text { Economia } \\
\text { (l/hab.dia) }\end{array}$ \\
\hline Descarga Bacia Sanitária & $\begin{array}{c}\text { Bacia Sanitária Caixa } \\
\text { Acoplada } 6 \text { litros }\end{array}$ & 28,00 & 0,00 & 28,00 \\
\hline Chuveiro & Ducha & 62,00 & 62,00 & 0,00 \\
\hline Torneiras & Torneira de Uso geral & 3,60 & 3,60 & 0,00 \\
\hline Cozinha & Torneira de Pia & 48,32 & 48,32 & 0,00 \\
\hline Lavar roupas & Torneira de Uso geral & 11,00 & 0,00 & 11,00 \\
\hline Utilização em comum & Torneira de Uso geral & 21,30 & 0,00 & 21,30 \\
\hline \multicolumn{4}{|c|}{ ECONOMIA DIÁRIA (I/hab) } & 60,30 \\
\hline \multicolumn{4}{|c|}{ ECONOMIA MENSAL (l/hab) } & $\mathbf{1 8 0 9 , 0 0}$ \\
\hline
\end{tabular}

\subsubsection{Sistema de captação de água pluvial juntamente com os equipamentos economizadores}

Se for considerada a utilização simultânea do sistema de captação de água pluvial juntamente com os equipamentos economizadores, a economia de água será de 109,1 litros de água potável por habitante, por dia, conforme apresentado na tabela 9, que relaciona a quantidade de litros utilizada antes da utilização dos sistemas, depois da instalação dos mesmos e quanto isso representa de economia, diária e mensal. 
Tabela 9: Redução de consumo diário com a utilização dos dois sistemas simultaneamente.

\begin{tabular}{ccccc}
\hline Uso & $\begin{array}{c}\text { Equipamento } \\
\text { Economizador }\end{array}$ & $\begin{array}{c}\text { Antes } \\
(1 / \text { hab.dia })\end{array}$ & $\begin{array}{c}\text { Depois } \\
(\mathrm{l} / \mathrm{hab} . d i a)\end{array}$ & $\begin{array}{c}\text { Economia } \\
(\mathrm{l} / \mathrm{hab} . d i a)\end{array}$ \\
\hline $\begin{array}{c}\text { Descarga Bacia } \\
\text { Sanitária }\end{array}$ & $\begin{array}{c}\text { Bacia VDR com } \\
\text { acionamento seletivo }\end{array}$ & 28,00 & 0,00 & 28,00 \\
Chuveiro & Restritor de Vazão & 62,00 & 42,16 & 19,84 \\
Torneiras & Arejador Vazão & 3,60 & 1,37 & 2,23 \\
Cozinha & Arejador Vazão & 48,32 & 20,78 & 27,54 \\
Lavar roupas & Regulador de Vazão & 11,00 & 0,00 & 11,00 \\
Utilização em & Regulador de Vazão & 21,30 \\
comum & ECONOMIA DIÁRIA (1/hab) & 0,00 & 21,30 \\
\hline \multicolumn{5}{c}{ ECONOMIA MENSAL (1/hab) } \\
\hline \multicolumn{5}{c}{}
\end{tabular}

\subsubsection{Consumo e redução de água de acordo com cada sistema}

Antes da aplicação de qualquer sistema de economia havia a necessidade de 20,97 $\mathrm{m}^{3}$ de água potável por mês na residência para atender adequadamente seus habitantes. Após a implantação do sistema de captação de água pluvial obteve-se uma redução no consumo de $34,59 \%$, com os equipamentos economizadores de água uma redução de $44,16 \%$ e com a implantação dos dois sistemas de economia obteve-se uma redução de consumo de 63,08\% de água potável na residência.

\subsection{Quantificação e orçamentação dos materiais}

Os materiais necessários para o sistema de captação de água pluvial estão apresentados na Tabela 10, sendo que esses materiais foram levantados e dimensionados levando em consideração as recomendações descritas nas normas NBR 10844 (ABNT, 1989) Instalações prediais de águas pluviais - Procedimento e pela NBR 15527 (ABNT, 2007) Água de chuva - Aproveitamento de coberturas em áreas urbanas para fins não potáveis - Requisitos. Os valores apresentados nesta tabela foram obtidos através do orçamento feito em empresas da região.

Tabela 10: Quantificação dos Materiais.

\begin{tabular}{cccc}
\hline Material & Quantidade & Valor unitário & Valor total \\
\hline Caixa d'agua 20001 & 2 & $\mathrm{R} \$ 652,50$ & $\mathrm{R} \$ 1.305,00$ \\
Bomba d'água 1/2 CV & 1 & $\mathrm{R} \$ 200,00$ & $\mathrm{R} \$ 200,00$ \\
Válvula de Retenção & 1 & $\mathrm{R} \$ 50,00$ & $\mathrm{R} \$ 50,00$ \\
Filtro de Limpeza & 1 & $\mathrm{R} \$ 700,00$ & $\mathrm{R} \$ 700,00$ \\
Tubos, curvas, joelhos & - & - & $\mathrm{R} \$ 200,00$ \\
Clorador & 1 & $\mathrm{R} \$ 200,00$ & $\mathrm{R} \$ 200,00$ \\
Freio d'água & 1 & $\mathrm{R} \$ 90,00$ & $\mathrm{R} \$ 90,00$ \\
Sifão Ladrão & 1 & $\mathrm{R} \$ 195,00$ & $\mathrm{R} \$ 195,00$ \\
Realimentador Residencial & 1 & $\mathrm{R} \$ 350,00$ & $\mathrm{R} \$ 350,00$ \\
\hline
\end{tabular}


Os equipamentos economizadores de água foram levantados de acordo com a necessidade dos mesmos na residência e especificado em memorial, apresentados na tabela 11 .

Tabela 11: Quantificação de Equipamentos Economizadores.

\begin{tabular}{ccccc}
\hline Uso & Equipamento Economizador & Quantidade & $\begin{array}{c}\text { Valor } \\
\text { unitário }\end{array}$ & $\begin{array}{c}\text { Valor } \\
\text { total }\end{array}$ \\
\hline $\begin{array}{c}\text { Bacia } \\
\text { Sanitária }\end{array}$ & Diferença de valor Bacia VDR Acionamento \\
duplo. & 3 & $\mathrm{R} \$ 70,00$ & $\begin{array}{c}\mathrm{R} \$ \\
210,00\end{array}$ \\
Chuveiro & Restritor de Vazão de 8 litros por minuto & 3 & $\mathrm{R} \$ 10,00$ & $\mathrm{R} \$ 30,00$ \\
$\begin{array}{c}\text { Lavatório/ } \\
\text { Banheiro } \\
\begin{array}{c}\text { Torneira/Uso } \\
\text { Geral }\end{array}\end{array}$ & Arejador de Vazão de 4,5 litros por minuto & 3 & $\mathrm{R} \$ 20,00$ & $\mathrm{R} \$ 60,00$ \\
$\begin{array}{c}\text { Torneira/ Pia } \\
\text { Regulador de Vazão de 13 litros por minuto }\end{array}$ & 4 & $\mathrm{R} \$ 10,00$ & $\mathrm{R} \$ 40,00$ \\
\hline & Arejador Vazão de 6 litros por minuto & 2 & $\mathrm{R} \$ 12,00$ & $\mathrm{R} \$ 24,00$ \\
\hline
\end{tabular}

\subsection{Análise da Viabilidade Econômica}

A análise econômica de um projeto permite fazer estimativas de todo o gasto envolvido com o investimento inicial, operação, manutenção e receitas geradas durante um determinado período de tempo, para que se possa montar o fluxo de caixa relativo a esses investimentos, custos e receitas e determinar as estimativas dos indicadores econômicos do projeto (LINDEMEYER, 2008).

Depois de definir o horizonte da análise, coletar os dados relevantes, elaborar as estimativas de fluxo de caixa e obter os custos de financiamento, o passo seguinte é a elaboração da perspectiva do investimento (BRUNI; FAMÁ, 2003).

Podem ser admitidos diferentes indicadores como resultados de um fluxo de caixa. A adoção de um indicador em especial é função do objetivo da análise a ser considerada. Três indicadores comumente utilizados nas análises de viabilidade econômica de empreendimentos são o Valor Presente Líquido (VPL), a Taxa Interna de Retorno e o período de recuperação do investimento (payback) (SILVA, 2008).

O método do Valor Presente Líquido analisa o fluxo de caixa, através do cálculo do valor presente, levando em consideração a Taxa Mínima de Atratividade, no caso de 8\%. Caso o VPL for positivo o investimento é desejável. Se o VPL for negativo, indica que o investimento não é bom. Para cada um dos 3 sistemas de economia de água foi realizado o cálculo do VPL

A Taxa Interna de Retorno (TIR) é utilizada para medir a rentabilidade de um investimento. Para esse investimento ser rentável, a TIR deve ser maior que a TMA esperada pelo investidor de $8 \%$.

O Payback simples realiza a determinação do tempo do retorno do investimento inicial, sem levar em consideração a correção do dinheiro em relação ao tempo, já o Payback descontado realiza 
a determinação do tempo do retorno do investimento inicial, levando em consideração a correção do dinheiro em relação ao tempo com a taxa mínima de atratividade.

\section{RESULTADOS}

\subsection{Valores para implantação}

$\mathrm{Na}$ tabela 12 está representado os valores referentes às instalações hidráulicas na residência para cada sistema. O valor inicial para o sistema convencional foi de acordo com consulta de preços locais. Para análise da viabilidade será considerado apenas a diferença de valor entre os mesmos.

Tabela 12: Quantificação dos Materiais.

\begin{tabular}{cccc}
\hline Custos instalações hidráulicas e sanitárias \\
\hline Sem sistema & $\begin{array}{c}\text { Com equipamentos } \\
\text { economizadores }\end{array}$ & $\begin{array}{c}\text { Com captação de } \\
\text { água pluvial }\end{array}$ & $\begin{array}{c}\text { Com ambos os } \\
\text { sistemas }\end{array}$ \\
\hline R\$ 5.000,00 & $\mathrm{R} \$ 5.364,00$ & $\mathrm{R} \$ 8.290,00$ & $\mathrm{R} \$ 8.654,00$ \\
\hline Acréscimo & $7,28 \%$ & $65,80 \%$ & $73,08 \%$ \\
\hline
\end{tabular}

\subsection{Valores para o consumo de água}

Os valores referentes à conta de água são estabelecidos pela concessionária. O projeto residencial em estudo enquadra-se como residencial $\mathrm{B}$, onde o valor de cada metro cúbico de água excedente será de $\mathrm{R} \$ 4,40 / \mathrm{m}^{3}$ com uma tarifa mínima de $\mathrm{R} \$ 20,83$.

Na tabela 13 está representado os custos com conta de água mensal e anual para cada sistema, enquanto na tabela 14 está representada a economia que o sistema realiza. Pode-se observar que o proprietário da residência pode economizar até $\mathrm{R} \$ 58,03$ mensais. Deve se levar em consideração que o sistema de captação de água pluvial requer uma manutenção anual que custa em torno $\mathrm{R} \$ 30,00$. Os valores de coleta e tratamento do esgoto não foram considerados, focando apenas na parte de água.

Tabela 13: Custo mensal e anual com água.

\begin{tabular}{|c|c|c|}
\hline Tipo de sistema & Custo mensal & Custo anual \\
\hline Convencional & $\mathrm{R} \$ \quad 112,79$ & $\mathrm{R} \$ 1.353,48$ \\
\hline Captação de água pluvial & $\mathrm{R} \$ \quad 80,98$ & $\mathrm{R} \$ 971,74$ \\
\hline Equipamentos economizadores & 72,18 & $\mathrm{R} \$ 866,14$ \\
\hline Captação de água pluvial + Equipamentos economizadores & 54,75 & $\mathrm{R} \$ 657,05$ \\
\hline
\end{tabular}


Tabela 14: Economia mensal e anual com água.

\begin{tabular}{ccccr}
\hline Tipo de sistema & $\begin{array}{c}\text { Economia } \\
\text { mensal }\end{array}$ & \multicolumn{2}{c}{$\begin{array}{c}\text { Economia } \\
\text { anual }\end{array}$} \\
\hline Convencional & $\mathrm{R} \$ 0,00$ & $\mathrm{R} \$$ & 0,00 \\
Captação de água pluvial & $\mathrm{R} \$ 31,81$ & $\mathrm{R} \$$ & 351,74 \\
Equipamentos economizadores & $\mathrm{R} \$ 40,61$ & $\mathrm{R} \$$ & 487,34 \\
Captação de água pluvial + Equipamentos & $\mathrm{R} \$ 58,03$ & $\mathrm{R} \$$ & 666,38 \\
economizadores & & & & \\
\hline
\end{tabular}

\subsection{Análise de viabilidade econômica entre os sistemas}

A análise da viabilidade econômica entre os sistemas realizou-se em cima do fluxo de caixa financeiro com o investimento inicial e o valor economizado anualmente com água potável em um horizonte de investimento de 15 anos, considerando uma taxa mínima de atratividade de 8\%. Os cálculos foram realizados através do Valor Presente Líquido (VPL), a taxa interna de retorno (TIR), do Payback Simples e do Payback Descontado.

Com os fluxos de caixa pode-se observar que para o sistema de equipamentos economizadores de água juntamente com o sistema de captação de água pluvial em 15 anos de utilização obteve-se VPL positivo, com um valor de R\$ 2049,8, uma TIR de 16,56\% (superior a TMA) e um período de recuperação de investimento (Payback Descontado) em 8 anos e 7 meses, tornando-se viável de acordo com todos os indicadores.

A figura 4 representa o gráfico com o fluxo de caixa, onde pode-se perceber claramente a superioridade dos equipamentos economizadores de água economicamente em relação aos outros sistemas. Este sistema mostrou-se mais atrativo em todas as análises, portanto o mais indicado.

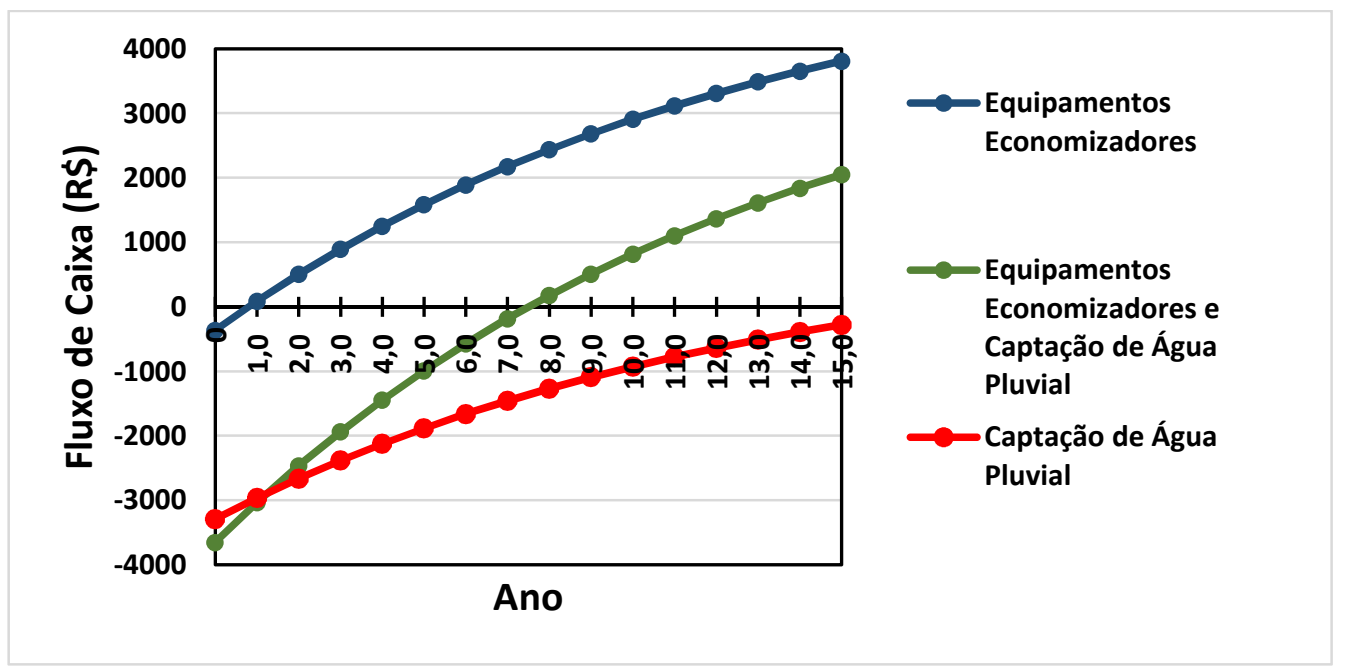

Figura 4: Gráfico Comparativo.

O sistema de equipamentos economizadores de água em 15 anos de utilização obteve-se o VPL positivo com um valor R\$ 3807,3, uma TIR de 133,88\% (superior a TMA) e um período de recuperação de investimento (Payback Descontado) em 10 meses de utilização, tornando-se viável economicamente, devido seus bons resultados. Além disso, possui benefícios ambientais, pois além 
de preservar a água potável, esses equipamentos diminuem a quantidade de esgoto, já que o mesmo é em função da água, e com a diminuição de lançamento de esgoto também há proteção dos recursos hídricos.

Para o sistema de captação de água pluvial, em 15 anos de utilização, obteve-se VPL negativo, em -R\$ 279,2, uma TIR de 6,58\% (inferior a TMA) e um período de recuperação de investimento (Payback Descontado) de 18 anos, fora do período em estudo tornando-se inviável economicamente. Porém se a TMA for reduzida para $6 \%$ a.a. o sistema é viável.

Destaca-se que há previsão de aumento no preço da água em um futuro próximo em que a oferta de água potável será menor do que a demanda. Além disso, há benefícios ambientais, principalmente se for avaliado em grande escala, onde com esse sistema diminui a água escoada com redução de enchentes e preservação dos recursos hídricos.

\section{CONCLUSÕES}

Dentre os sistemas avaliados, o sistema de equipamentos economizadores de água mostrouse tecnicamente mais viável a curto e a longo prazo, apresentando redução significativa no valor das contas de água, tanto em comparação com a implantação simultânea do sistema de captação de água pluvial juntamente com os equipamentos economizadores, quanto no sistema de captação pluvial por si só.

Duas das alternativas se pagam durante o período de utilização, considerando a taxa mínima de atratividade, onde a utilização de equipamentos economizadores de água o retorno do capital investido é de 10 meses e o sistema de captação de água pluvial juntamente com os equipamentos o retorno é a partir de 8 anos e 7 meses.

O sistema de captação de água pluvial não apresentou período de retorno durante o horizonte de estudo, porém ressalta-se que a não indicação deste sistema por si só considera apenas os fins financeiros, pois o mesmo representa uma redução de $34,6 \%$ no consumo de água potável, considerado eficiente diante de fins ambientais.

A perspectiva do desequilíbrio entre a oferta e demanda de água potável indica que futuramente haverá aumentos consideráveis no custo da água, valorizando estes sistemas e os tornando cada vez mais atrativos.

É válido ressaltar que cada região possui seu próprio aspecto e perfil, cada residência possui variadas características que devem ser analisadas separadamente. Portanto, é recomendável antes da aplicação destes sistemas uma consulta com profissionais do ramo para determinar o que é mais válido para cada caso para que o aproveitamento seja melhor aproveitado e que atenda aos objetivos do consumidor. 


\section{REFERÊNCIAS}

ABNT - Associação Brasileira de Normas Técnicas - NBR 10844: Instalações prediais de águas pluviais - Procedimento. Rio de Janeiro. 1989.

ABNT - Associação Brasileira de Normas Técnicas - NBR 15527: Agua de chuva Aproveitamento de coberturas em áreas urbanas para fins não potáveis - Requisitos. Rio de Janeiro. 2007.

BOKOVA, I. Message from Ms Irina Bokova, Director-General of UNESCO on the occasion of the World Water day. 2015. Disponível em: $<$ http://unesdoc.unesco.org/images/0023/002322/232250e.pdf>. Acesso em: 15 mar. 2016.

BRUNI, A. L.FAMÁ, R. As decisões de investimentos. São Paulo: Atlas, 2003.

CORSAN, COMPANIA RIOGRANDENSE DE SANEAMENTO. 2015. Disponível em: $<$ http://www.corsan.com.br/upload/arquivos/201512/16095649-tabela-tarifaria-municipiosregulados-pela-agergs.pdf $>$. Acesso em: 24 mar. 2016.

FECOMERCIO. O uso racional da água no comércio. 2010. 56f. Federação do Comércio de São Paulo, São Paulo.

LINDEMEYER, R. M. Análise da viabilidade econômico-financeira do uso do biogás como fonte de energia elétrica. Trabalho de Conclusão de curso. Universidade Federal de Santa Catarina. Florianópolis, 2008.

MAY, S. Estudo da viabilidade do aproveitamento de água de chuva para consumo não potável em edificações. 2004. 189f. Dissertação (Mestrado). Escola Politécnica da Universidade de São Paulo. Departamento de Engenharia de Construção Civil, São Paulo.

ONU. Até 2030 planeta pode enfrentar déficit de água de até 40\%. 2015. Disponível em: $<$ https://nacoesunidas.org/ate-2030-planeta-pode-enfrentar-deficit-de-agua-de-ate-40-alertarelatorio-da-onu/> Acesso em: 16 mar. 2016.

O2 ENGENHARIA. Aproveitamento da água da chuva. 2008. Disponível em: $<$ http://o2engenharia.com.br/index.php/atuacao/projetos\#2/> Acesso em: 17 mar. 2016.

PEREIRA, N. C. S.; SANTOS, D. F. A. Projeto de residência unifamiliar com tecnologia de sustentabilidade das principais instalações. 2013. 157f. Vol1. Trabalho de Conclusão de Curso (Engenharia Civil). Universidade da Amazônia. Centro de Ciências Exatas e tecnologia, Belém.

SCORTEGAGNA, V.; DA SILVA, J. M.; FERNANDES, V. M. C. Diagnóstico preliminar do consumo de água em aeroporto de pequeno porte. XIII Encontro Nacional de Tecnologia do Ambiente Construído, 2010, Canela-RS.

SILVA, J. R. da. Análise da viabilidade econômica da produção de peixes em tanques-rede no reservatório de Itaipu. Dissertação. Universidade Federal de Santa Maria, Santa Maria, 2008. 
SISTEMA NACIONAL DE INFORMAÇÕES SOBRE SANEAMENTO - SNIS. Diagnósticos dos serviços de água e esgotos - 2014. 2016. 212f. Brasília.

TOMAZ, P. Coeficiente de Runoff. 2009. Disponível em: $<$ http://www.pliniotomaz.com.br/downloads/livros/Livro_aprov._aguadechuva/Capitulo\%2005.pdf $>$ Acesso em: 27 mar. 2016. 